\title{
SISTEM INFORMASI PENJUALAN ALAT BERAT DAN SPAREPARTS PADA PT. HEXINDO MENGGUNAKAN BARCODE
}

\author{
Ita Arfyanti ${ }^{1)}$, Azhari Lathyf ${ }^{2)}$, Didin Rosita Arini ${ }^{3)}$ \\ ${ }^{1,3}$ Sistem Informasi, STMIK Widya Cipta Dharma \\ ${ }^{2}$ Teknik Informatika, STMIK Widya Cipta Dharma \\ 1,2,3 J1. Prof. M. Yamin No. 25, Samarinda, 75123 \\ E-mail : qonita23@yahoo.com ${ }^{1)}$, informatikawicida@gmail.com ${ }^{2}$, didin_rossy@yahoo.com ${ }^{3)}$
}

\begin{abstract}
ABSTRAK
Sistem informasi adalah sebuah sistem yang terdiri atas rangkaian subsistem informasi terhadap pengolahan data untuk menghasilkan informasi yang berguna. Sistem informasi penjualan alat berat dan spareparts merupakan pengalihan alat berat dan spareparts dengan imbalan uang sebagai gantinya dengan persetujuan untuk menyerahkan barang kepada pihak lain dengan menerima pembayaran. Barcode sebagai kumpulan kode yang berbentuk garis, dimana masing-masing ketebalan setiap garis berbeda sesuai dengan isi kodenya. PT. Hexindo Adi Perkasa merupakan perusahaan yang bergerak dalam bidang penjualan alat berat dan spareparts yang berada di Samarinda Kalimantan Timur.
\end{abstract}

Penelitian ini dilakukan dalam rangka membangun sistem informasi penjualan alat berat dan spareparts pada PT. Hexindo Adi Perkasa Samarinda menggunakan Barcode. Adapun metode pengumpulan data yang dilakukan adalah wawancara, observasi dan studi pustaka. Sedangkan untuk metode pengembangan sistem alat bantu yang digunakan adalah Flow of Documents, Contex Diagram, Data Flow Diagram, HIPO.

Dengan dibangunnya sistem informasi penjualan alat berat dan spareparts pada PT. Hexindo Adi Perkasa Samarinda ini pengguna dapat memproses data lebih praktis, cepat dan akurat menggunakan perangkat barcode reader.

Kata Kunci: Sistem Informasi, Penjualan, Alat Berat, Spareparts, Barcode,

\section{PENDAHULUAN}

PT Hexindo Adi Perkasa adalah Perusahaan yang bergerak di bidang pengadaan alat berat dan pemegang merek resmi untuk alat-alat berat dan suku cadang bermerek Hitachi di Indonesia. Di era globalisasi seperti sekarang ini komputer merupakan salah satu hal yang sangat penting karena hampir semua aspek kehidupan manusia telah memanfaatkan tekhnologi informasi ini contohnya saja dalam berbagai bidang pekerjaan yang di kerjakan, baik itu di kantor pemerintah ataupun di kantor milik swasta pada umumnya telah menggunakan sistem komputerisasi.

Kebutuhan akan sistem penjualan alat berat yang sedang berjalan saat ini, pengelolaan data yang meliputi pencarian, pemasukan, pengeditan dan penghapusan data, kadangkala memakan waktu yang cukup lama, dimana petugas kadangkala kesulitan mencari data alat bulan sebelumnya serta berapa alat berat yang masuk dan yang terjual.

Berdasarkan permasalahan diatas, keberadaan aplikasi penjualan alat berat sangat dibutuhkan sekarang ini. Sistem informasi penjualan alat berat dapat membantu bagian administrasi dalam memproses penjualan alat berat secara cepat, tepat dan akurat.

\section{RUANG LINGKUP PENELITIAN}

Dalam penelitian ini permasalahan mencakup:

1. Bagaimana Membangun Suatu Sistem Informasi Penjualan Spare Parts Dan Alat Berat Pada PT. Hexindo Adi Perkasa Tbk Samarinda ?".

2. Batasan Masalah $=$

1. Inputan Data

1. Input Data Admin

2. Input Master Unit

3. Input Master Suku Cadang

4. Input Pelanggan

5. Input Suku Cadang Pengganti

2. Proses

1. Transaksi Unit Masuk

2. Transaksi Suku Cadang Masuk

3. Transaksi Penjualan Suku Cadang

4. Transaksi Penjualan Unit

3. Output

1. Laporan Penjualan Unit

2. Laporan Penjualan Suku Cadang

3. Laporan Pelanggan

4. Laporan Master Unit Alat Berat

5. Laporan Master Unit Alat Berat Masuk

6. Laporan Stok Unit Alat Berat 
7. Laporan Master Suku Cadang

8. Laporan Master Suku Cadang Masuk

9. Laporan Stok Suku Cadang

10. Grafik Penjualan Suku Cadang

11. Grafik Penjualan Unit Alat Berat

3. Tujuan penelitian untuk menghasilkan sistem informasi penjualan alat berat dengan lebih mengoptimalkan teknologi komputer sehingga memberikan kemudahan bagi perusahaan dalam melakukan pekerjaan.

\section{BAHAN DAN METODE}

\subsection{Sistem Informasi}

Sistem informasi adalah sebuah sistem yang terdiri atas rangkaian subsistem informasi terhadap pengolahan data untuk menghasilkan informasi yang berguna dalam pengambilan keputusan (Kusrini \& Andri Koniyo,2007).

\subsection{Metode Air Terjun}

Model SDLC air terjun (waterfall) sering juga disebut model sekuensial linier (sequential linear) atau alur hidup klasik (classic life cycle). Model air terjun menyediakan pendekatan alur hidup perangkat lunak secara sekuensial atau terurut dimulai dari analisis, desain, pengodean, pengujian, dan tahap pendukung (support) pemeliharaan (maintenance).

1. Analisis kebutuhan perangkat lunak Proses pengumpulan kebutuhan dilakukan secara intensif untuk mespesifikasikan kebutuhan perangkat lunak agar dapat dipahami perangkat lunak seperti apa yang dibutuhkan oleh user. Spesifikasi kebutuhan perangkat lunak pada tahap ini diperlukan untuk didokumentasikan.

2. Desain

Desain perangkat lunak adalah proses multilangkah yang fokus pada desain pembuatan program perangkat lunak termasuk struktur data, arsitektur perangkat lunak, representasi antarmuka, dan prosedur pengodean. Tahap ini mentranslasi kebutuhan perangkat lunak dari tahap analisis kebutuhan ke representasi desain agar dapat diimplementasikan menjadi program pada tahap selanjutnya.

3. Pembuatan kode program

Desain harus ditranslasikan ke dalam program perangkat lunak. Hasil dari tahap ini adalah komputer sesuai dengan desain yang telah dibuat pada tahap desain.

4. Pengujian

Fokus pada perangkat lunak dari segi lojik dan fungsional dan memastikan bahwa semua bagian sudah diuji. Hal ini dilakukan untuk meminimalisir kesalahan (error) dan memastikan keluaran yang dihasilkan sesuai dengan yang diinginkan.

5. Pendukung (support) atau pemeliharaan (maintenance)

Tidak menutup kemungkinan sebuah perangkat lunak mengalami perubahan ketika sudah dikirimkan ke user. Perubahan bisa terjadi karena adanya kesalahan yang muncul dan tidak terdeteksi saat pengujian atau perangkat lunak harus beradaptasi dengan lingkungan baru. Tahap pendukung atau pemeliharaan dapat mengulangi proses pengembangan mulai dari analisis spesifikasi untuk perubahan perangkat lunak yang sudah ada, tapi tidak untuk membuat perangkat lunak yang baru.(Pressman, 2002).

\subsection{Penjualan}

Penjualan merupakan pengalihan hak milik atas barang dengan imbalan uang sebagai gantinya dengan persetujuan untuk menyerahkan barang kepada pihak lain dengan menerima pembayaran. Keberhasilan usaha penjualan dapat dilihat dari volume penjualan yang didapat . Dengan kata lain, apakah usaha itu dapat laba atau tidak, sangat tergantung kepada keberhasilan penjualan itu. Matz dan usri (1988) dalam Rangkuti (2009).

\section{RANCANGAN SISTEM/APLIKASI}

\subsection{FOD Berjalan}

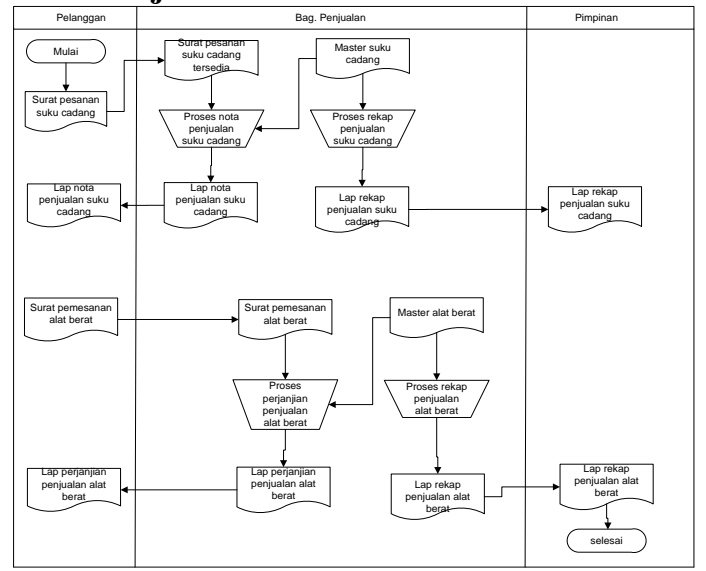

Gambar 1. FOD Berjalan

\subsection{FOD Diusulkan}

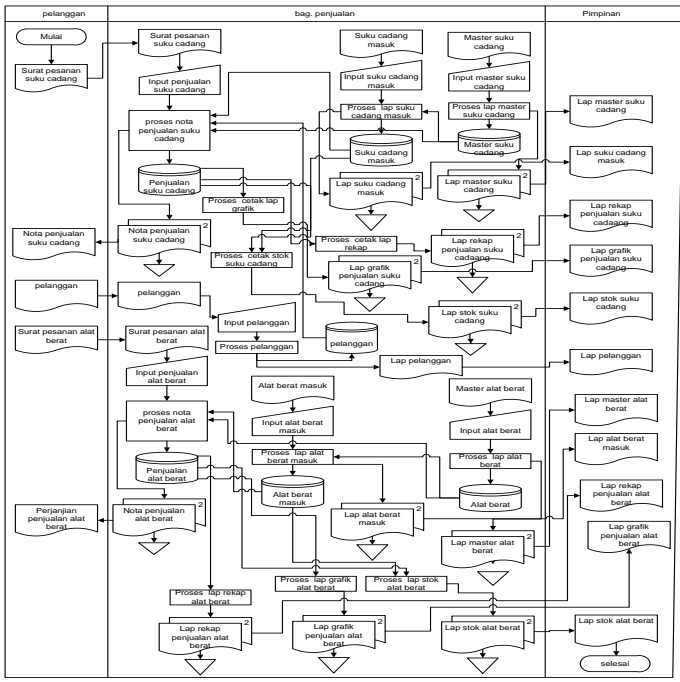

Gambar 2. FOD Diusulkan 


\subsection{Contex Diagram}

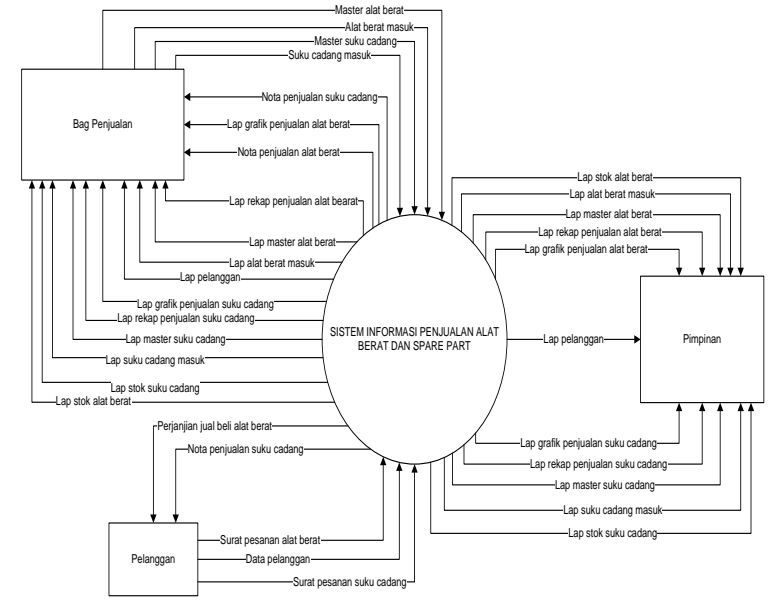

Gambar 3. Contex Diagram

\subsection{DFD Level 0}

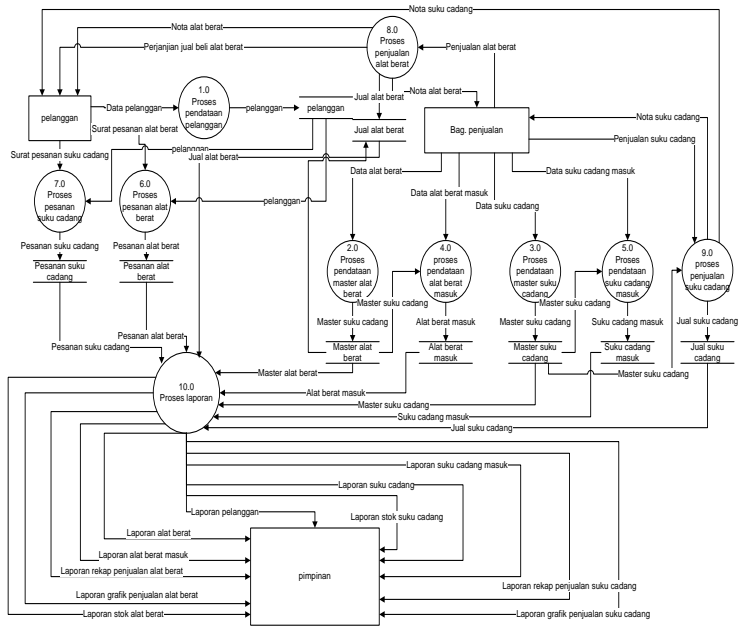

Gambar 4. DFD Level 0

\subsection{DFD Level 1}

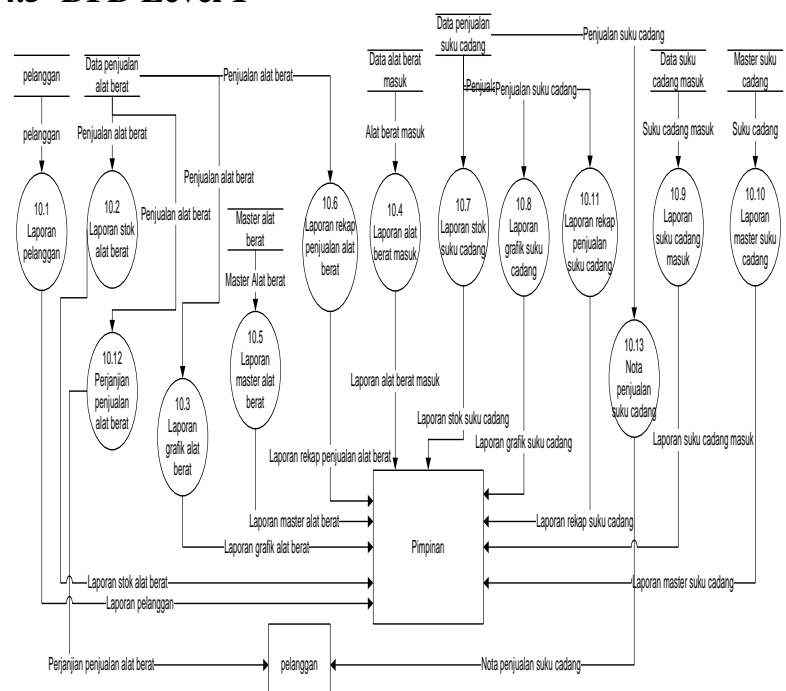

Gambar 5. DFD Level 1
4.6 HIPO

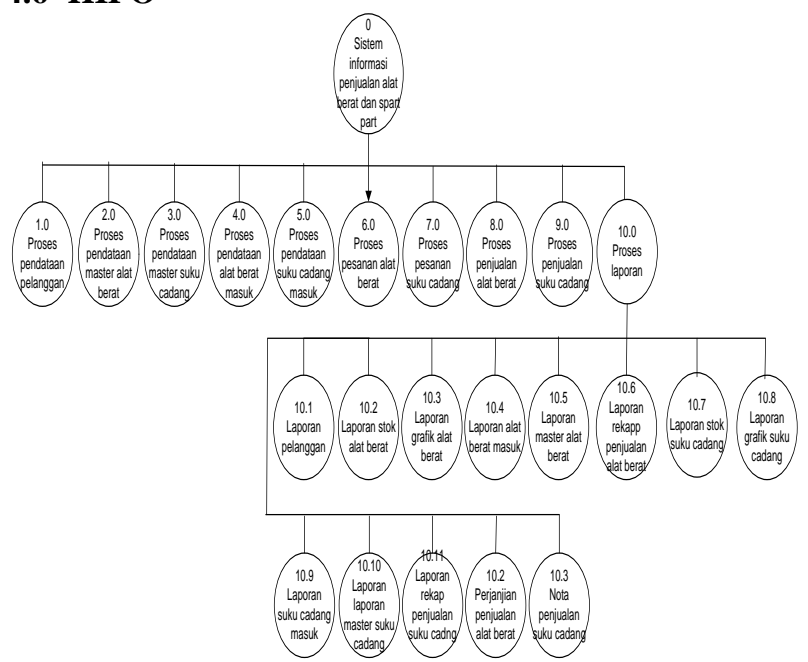

Gambar 6. HIPO

\subsection{Relasi Tabel}

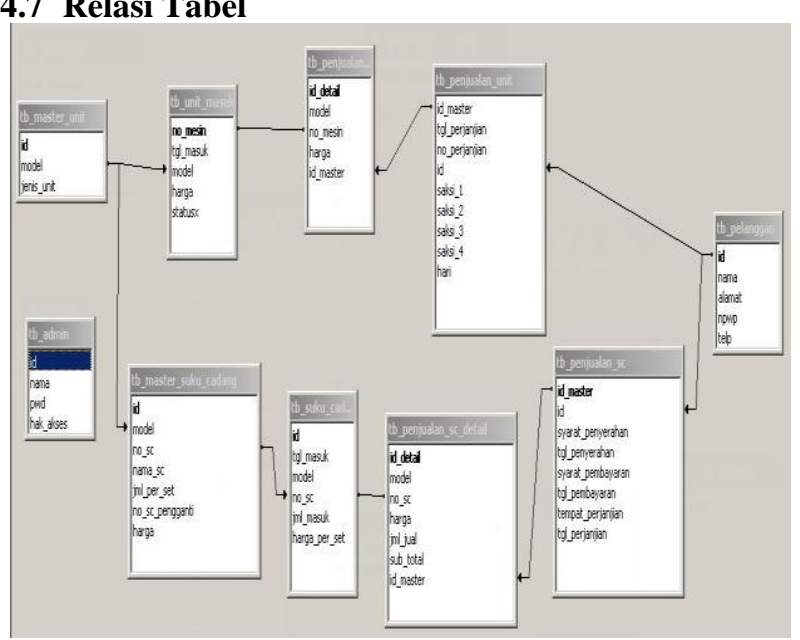

Gambar 7. Relasi Tabel

Tabel 1. Tabel master suku cadang

\begin{tabular}{|l|l|l|l|}
\hline Nama & Tipe & $\begin{array}{l}\text { Panja } \\
\text { ng }\end{array}$ & Keterangan \\
\hline Id & Number & 4 & Id \\
\hline Model & Text & 50 & Model \\
\hline No_sc & Text & 20 & No suku cadang \\
\hline Nama_sc & Text & 50 & Nama Suku cadang \\
\hline Jml_per_set & Number & 4 & Jumlah Per set \\
\hline Harga & Number & 10 & Harga \\
\hline
\end{tabular}

Tabel 2. Tabel master unit

\begin{tabular}{|l|l|l|l|}
\hline Nama & Tipe & $\begin{array}{l}\text { Panja } \\
\text { ng }\end{array}$ & Keterangan \\
\hline Id & Number & 4 & Id \\
\hline Model & Text & 50 & Model \\
\hline Jenis unit & Text & 50 & Jenis unit \\
\hline
\end{tabular}


Tabel 3. Tabel master suku cadang pengganti

\begin{tabular}{|l|l|l|l|}
\hline Nama & Tipe & $\begin{array}{l}\text { Panja } \\
\text { ng }\end{array}$ & Keterangan \\
\hline Model & Text & 50 & Model \\
\hline No_sc & Text & 10 & No suku cadang \\
\hline No_sc_pengganti & Text & 10 & $\begin{array}{l}\text { No suku cadang } \\
\text { pengganti }\end{array}$ \\
\hline
\end{tabular}

Tabel 4. Tabel penjualan suku cadang

\begin{tabular}{|l|l|l|l|}
\hline Nama & Tipe & $\begin{array}{l}\text { Panja } \\
\text { ng }\end{array}$ & Keterangan \\
\hline Id_master & Text & 10 & Id master \\
\hline Id & Text & 10 & Id \\
\hline $\begin{array}{l}\text { Syarat_penyera } \\
\text { han }\end{array}$ & Text & 225 & Syarat penyerahan \\
\hline Tgl_penyerahan & $\begin{array}{l}\text { Date/tim } \\
\text { e }\end{array}$ & 8 & Tanggal penyerahan \\
\hline $\begin{array}{l}\text { Syarat_pembaya } \\
\text { ran }\end{array}$ & Text & 225 & Syarat pembayaran \\
\hline $\begin{array}{l}\text { Tanggal_ } \\
\text { pembayaran }\end{array}$ & $\begin{array}{l}\text { Date/tim } \\
\text { e }\end{array}$ & 8 & $\begin{array}{l}\text { Tanggal } \\
\text { pembayaran }\end{array}$ \\
\hline $\begin{array}{l}\text { Tempat_perjanji } \\
\text { an }\end{array}$ & Text & 50 & Tempat perjanjian \\
\hline $\begin{array}{l}\text { Tgl_perjanjian } \\
\text { e }\end{array}$ & $\begin{array}{l}\text { Date/tim } \\
\text { enangan }\end{array}$ & 8 & Tanggal perjanjian \\
\hline
\end{tabular}

Tabel 5. Tabel penjualan unit

\begin{tabular}{|l|l|l|l|}
\hline Nama & Tipe & $\begin{array}{l}\text { Panja } \\
\text { ng }\end{array}$ & Keterangan \\
\hline Id_master & text & 10 & Id master \\
\hline Tgl_perjanjjian & $\begin{array}{l}\text { Date/tim } \\
\text { e }\end{array}$ & 8 & Tanggal perjanjian \\
\hline No_perjanjian & Text & 70 & No perjanjian \\
\hline Id & Text & 10 & Id \\
\hline Saksi_1 & Text & 40 & Saksi 1 \\
\hline Saksi_2 & Text & 40 & Saksi 2 \\
\hline Saksi_3 & Text & 40 & Saksi 3 \\
\hline Saksi_4 & Text & 40 & Saksi 4 \\
\hline hari & Text & 225 & \\
\hline
\end{tabular}

\section{IMPLEMENTASI}

5.1 Form mdi

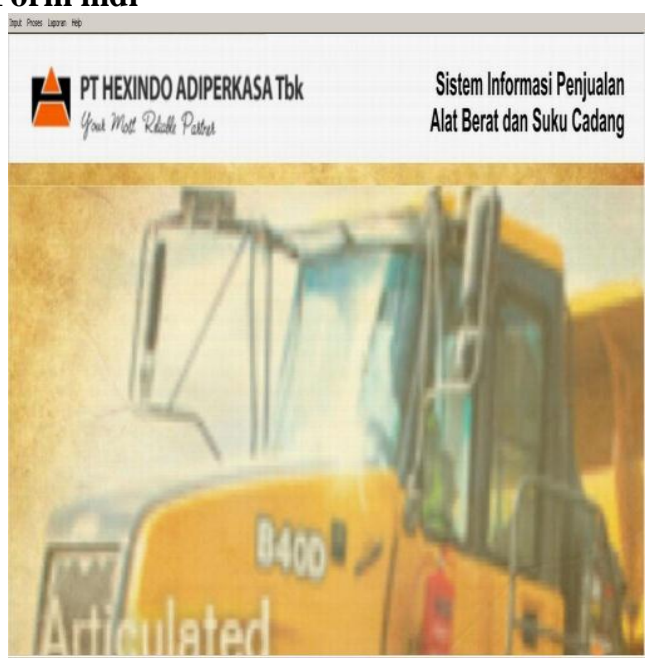

Gambar 8. Form mdi
5.2 Form suku cadang pengganti

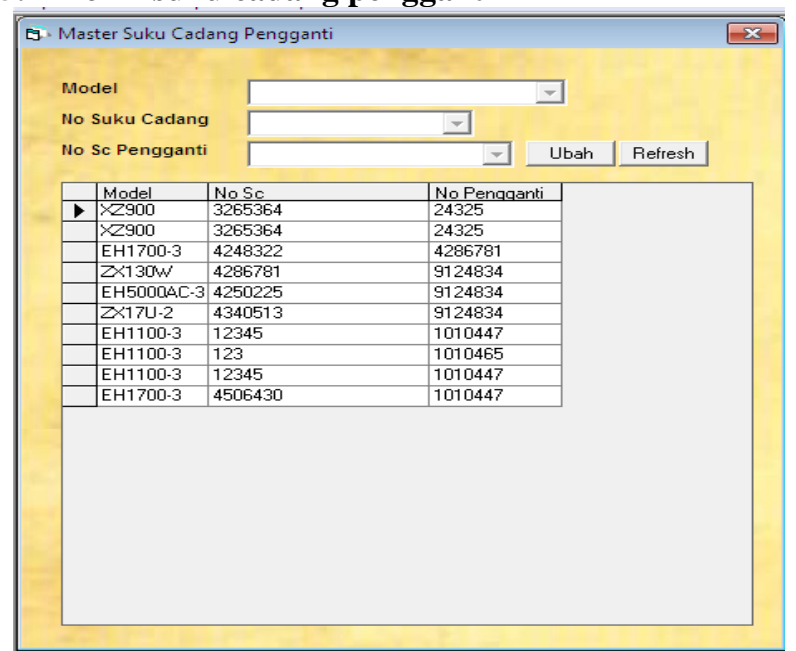

Gambar 9. Form suku cadang pengganti

\subsection{Form Master Unit}

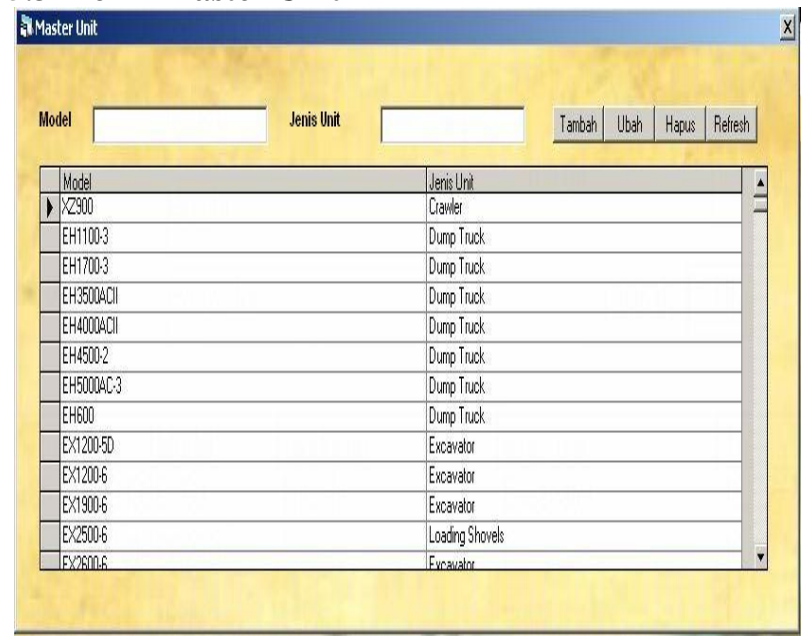

Gambar 10. Form master unit

\subsection{Form Penjualan unit}

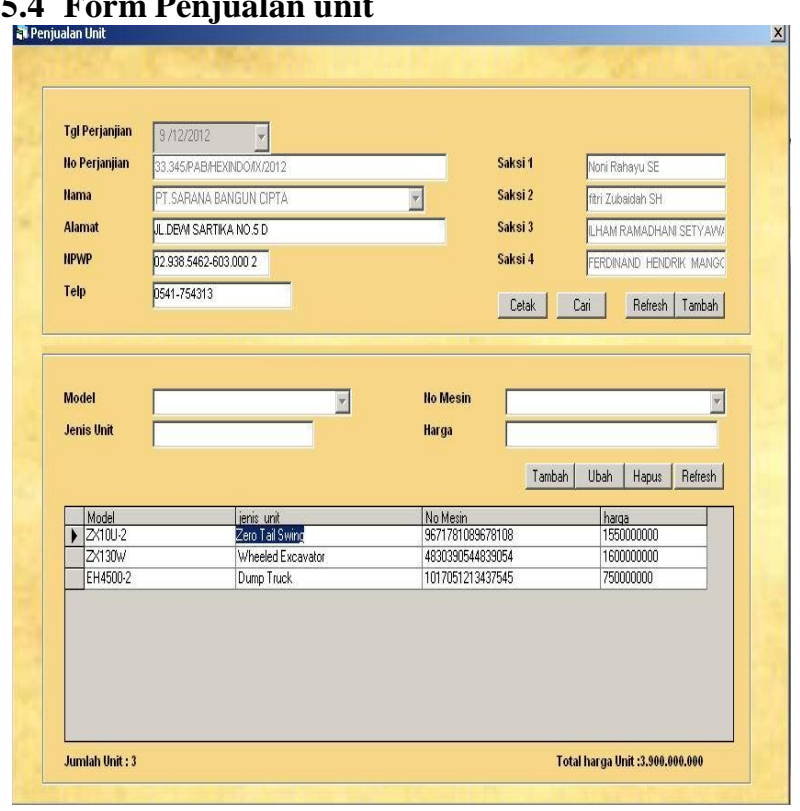

Gambar 11. Form penjualan unit 


\subsection{Master suku cadang}

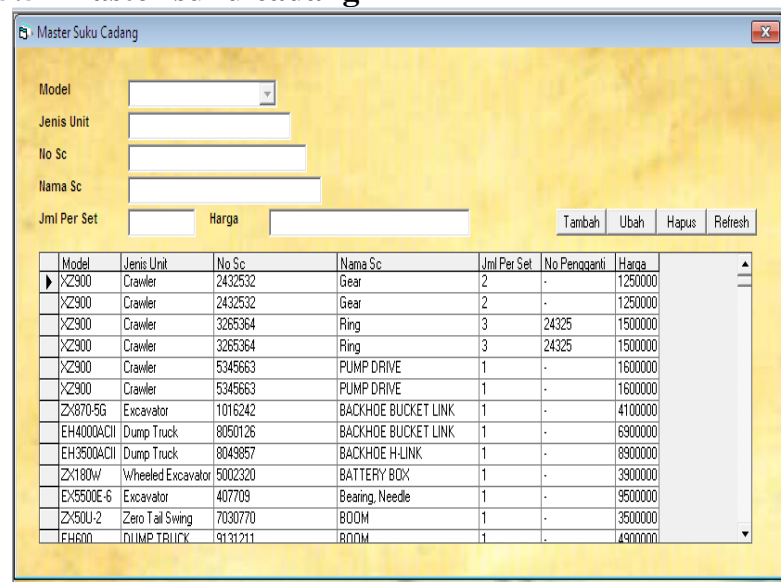

Gambar 12. Master suku cadang

\subsection{Penjualan suku cadang}

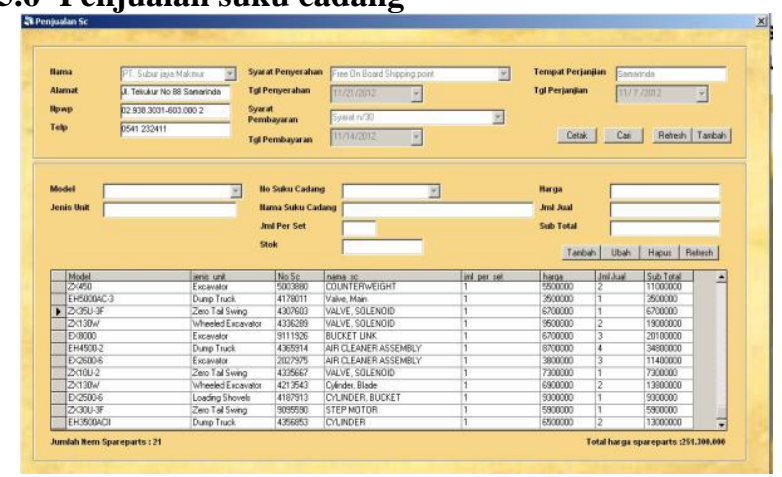

Gambar 13. Penjualan suku cadang

\subsection{Form laporan master unit}

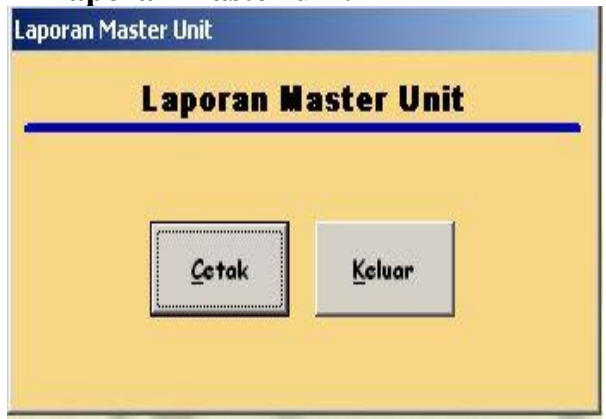

Gambar 14. Form laporan master unit

Berikut ini adalah tampilan laporan master unit / alat berat.

\subsection{Laporan master unit}

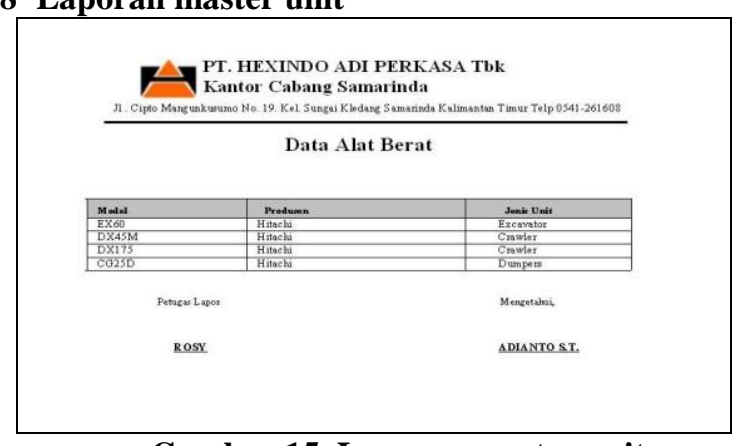

Gambar 15. Laporan master unit
5.9 Form smaster suku cadang

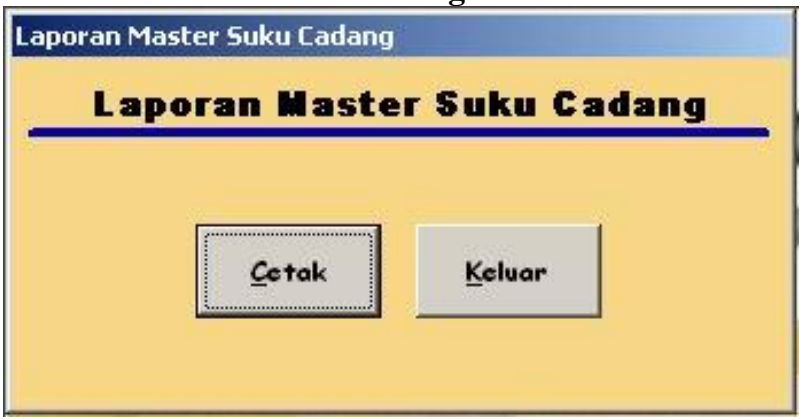

Gambar 16. Form master suku cadang

Berikut ini adalah tampilan laporan master suku cadang.

\subsection{Laporan master suku cadang}

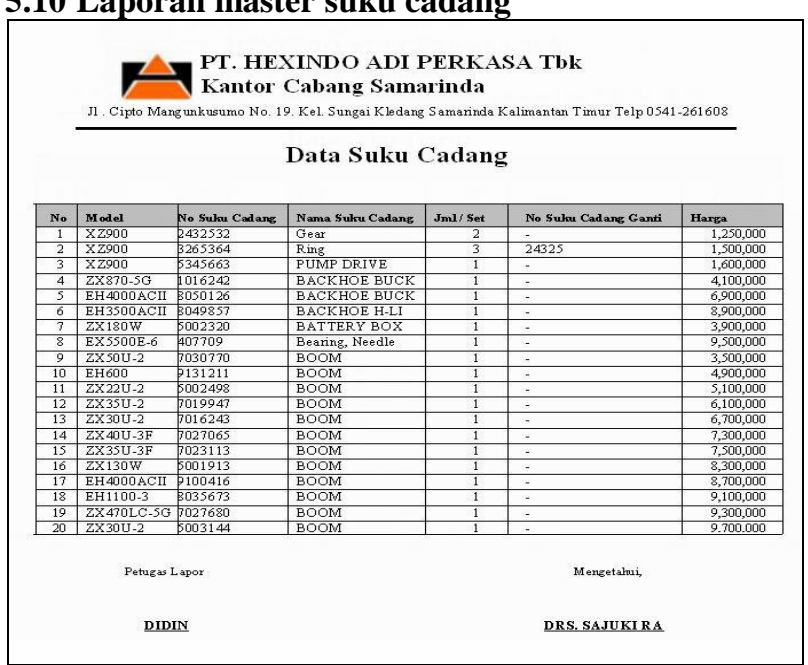

Gambar 17. Laporan master suku cadang

\subsection{Form grafik penjualan alat berat}

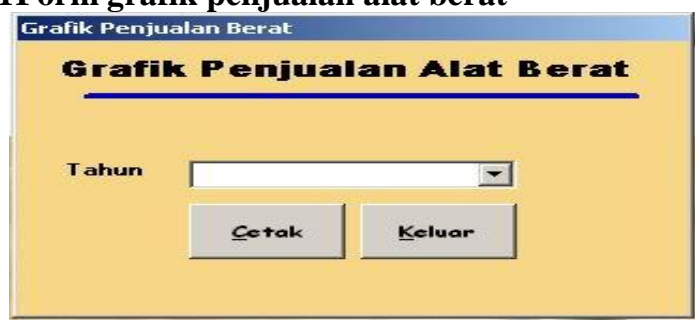

Gambar 18. Form penjualan alat berat

Berikut ini adalah tampilan laporan grafik penjualan alat berat.

5.12 Laporan grafik penjualan alat berat

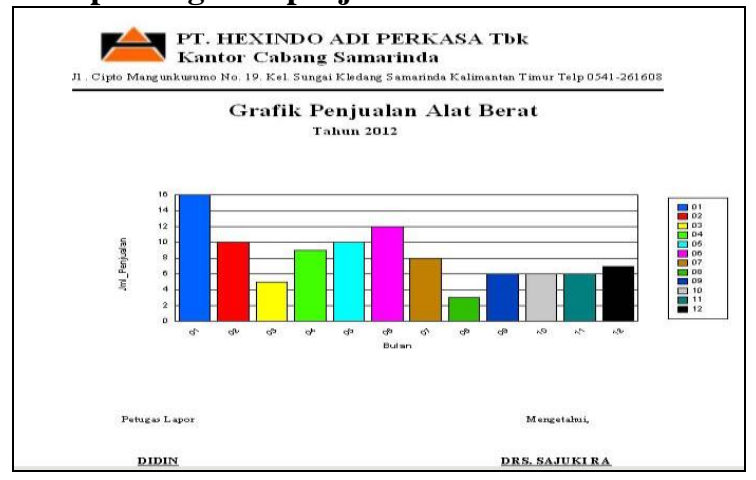

Gambar 19. Laporan grafik penjualan alat berat 
5.13Form grafik penjualan suku cadang

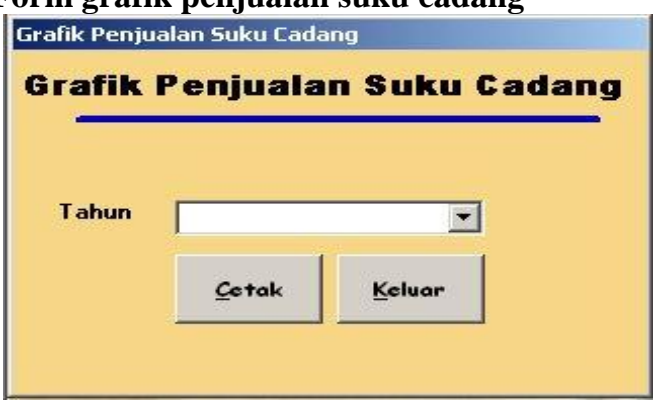

Gambar 20. Form grafik penjualan suku cadang

Berikut ini adalah tampilan laporan grafik penjualan suku cadang.

\subsection{Laporan grafik penjualan suku cadang}

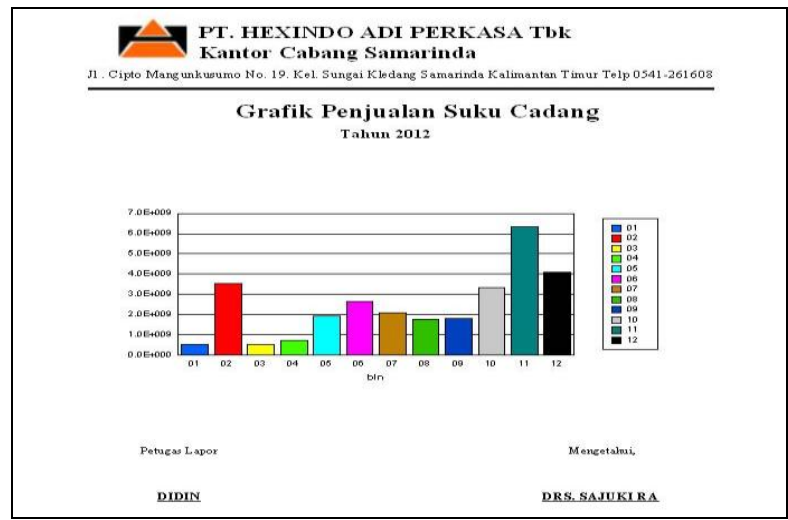

Gambar 21. Laporan grafik penjualan suku cadang

\section{KESIMPULAN}

Berdasarkan uraian dan pembahasan, maka penulis dapat mengambil kesimpulan sebagai berikut :

1. Dengan adanya sistem informasi penjualan alat berat dan spareparts pada PT. Hexindo Adi Perkasa Tbk ini, dapat membantu bagian penjualan dalam melakukan pemrosesan data penjualan secara cepat serta dapat mengetahui stok dan perkembangan penjualan dengan cepat dan akurat dalam mengoptimalkan teknologi komputer sehingga memberikan kemudahan bagi perusahaan dalam melakukan pekerjaan.

2. Dengan penggunaan barcode reader maka waktu pencarian nomor kode pada beberapa komponen spareparts alat berat menjadi lebih cepat dan akurat.

\section{SARAN}

Berdasarkan dari pembahasan yang telah diuraikan pada bab-bab sebelumnya, penulis memberikan beberapa saran-saran berikut :

1. Sistem ini dapat dikembangkan dalam jaringan supaya terhubung dengan bagian gudang untuk sinkronisasi data.

2. Sistem ini dapat dikembangkan menjadi sistem pakar diagnosis penyediaan unit dan suku cadang dengan algoritma algoritma diagnosis yang relevan.

\section{DAFTAR PUSTAKA}

Al Fatta, Hanif, 2007, Analisa dan perancangan sistem informasi untuk keunggulan bersaing perusahaan dan organisasi modern, Yogyakarta :Andi

Charles W. Lamb joseph F. Carl Mcdaniel, 2001, Pemasaran. Edisi Pertama, Salemba Empat, Jakarta

Fathansyah, 2007 , Buku Teks Komputer Basis Data Cetakan Keenam, Bandung : Bi-Obeses

Jogiyanto, 2003 , Analisis dan Desain Sistem Informasi Yogyakarta : Penerbit Andi Offset

Marlinda, 2004, Pengantar Sistem Informasi Manajemen, Andi Yogyakarta, Yogyakarta

Mc.leod, 2007, Sistem Informasi Manajemen, Yogyakarta : Penerbit Andi Offset

Rangkuti, Freddy, 2009, Strategi Promosi yang Kreatif \& Analisis Kasus Integrated Marketing Comunication, Jakarta : PT Gramedia Pustaka Utama.

Rachdian \& Andy Sikumbang, 2006, Mastering CMS dengan Mambo/Joomla, Jakarta: Elex Media Komputindo

Rosa dan Shalahuddin, 2011, Rekayasa Perangkat Lunak, Bandung : Modula

Supriyanto, Aji, 2005. Pengantar Teknologi Informasi, Semarang : Salemba Infotek. 